\title{
A Conceptual Study on Fundamentals and Characteristics of Embedded Systems
}

\author{
${ }^{1}$ VJST Anirudh, ${ }^{2}$ M. Kiran Kumar \\ ${ }^{1}$ Under Graduate, Guru Nanak Institutions Technical Campus, Hyderabad \\ ${ }^{2}$ Assistant Professor, Guru Nanak Institutions Technical Campus, Hyderabad \\ Kirann.intell@gmail.com \\ anirudhvjst@gmail.com
}

\begin{abstract}
An embedded system is an electronic/electro-mechanical system designed to perform a specific function and is a combination of firmware and hardware. A complete system on a chip is called an embedded system. It is a special purpose system in which the computer is encapsulated on a single chip which performs a specific task. Every system is unique and the hardware as well as the firmware is inevitable part of any product or equipment in all the fields including household appliances, telecommunications, medical equipment, consumer products etc. This paper highlights the fundamental concepts and characteristics of ES.

Keywords: Embedded Systems.
\end{abstract}

INTRODUCTION:

ES is an electronic/electro-mechanical system designed to perform a specific function and is a combination of firmware and hardware. A complete system on a chip is called an embedded system. It is a special purpose system in which the computer is encapsulated on a single chip which performs a specific task. Every system is unique and the hardware as well as the firmware is inevitable part of any product or equipment in all the fields including household appliances, telecommunications, medical equipment, consumer products etc.

Every embedded system is designed to perform a set of defined functions and they are developed in such a manner to do the specific task only.

Characteristics of Embedded Systems: Domain and application specific: - Every embedded system is designed to perform a set of defined functions and they are developed in such a manner to do the specific task only. For example, you can't replace the embedded control unit of your automatic washing machine with your microwave oven's embedded unit, because the control units of washing machine and microwave oven are designed in a special way such that they only perform specific tasks.
Real-time and reactive: - With the help of sensors the embedded system is in constant interaction with this real world which are connected to the input port od the system. So any changes in the real time world are captured by these sensors in real time and the control algorithm inside the unit reacts in a designed manner to bring the controlled output to the desired level. In response to the changes in the input the output will be changed in the system. A real time operating system means the timing behaviour of the system should be deterministic. Hence, a real time operating system should not miss any deadlines. Here let us consider an example of a car when it met with an accident the airbags should open as soon as the car gets hit in fraction of seconds it is a mission critical and deterministic.

\begin{tabular}{|c|c|}
\hline General purpose computing system & Embedded system \\
\hline - Contains a general-purpose operating & $\begin{array}{l}\text { - May or may not contain an operating } \\
\text { system for functioning }\end{array}$ \\
\hline - Applications are alterable by the user & $\begin{array}{l}\text { - The fim of the system is pre- } \\
\text { programmed, and it is non-alterable } \\
\text { by the user }\end{array}$ \\
\hline - Perfomance is the key deciding fact & $\begin{array}{l}\text { - Application specific requirements are } \\
\text { the key deciding factors }\end{array}$ \\
\hline in the selection of the system & Response requirements are not time \\
critical & $\begin{array}{l}\text { - Th response time requirements are } \\
\text { highly time critical }\end{array}$ \\
\hline - Need not be deterministic & - Execution behaviour is deteministic \\
\hline \hline
\end{tabular}

Fig: 1-Comparison of GPCS and ES

Operates in harsh environment: - They is no guarantee that all the embedded systems should be deployed in controlled 
Website: ijetms.in Issue:4, Volume No.4, July-2020 DOI: 10.46647/ijetms.2020.v04i04.004

environments. The environment where we deploy our embedded system may be a high temperature zone or dusty one or subjected to huge vibrations and shock. So, when our systems are placed in such areas, our system should be capable to withstand all the adverse operational conditions. For example, say we need to deploy a system in the desert area, which is a high temperature zone, then accordingly we need to use the components in building of the system which can withstand those high temperature grades[1].

Distributed: - An embedded system may be a part of larger systems. Combination of such systems forms a single embedded control unit. Let us consider an ATM as an example, the ATM contains many sub systems like a card reader embedded unit which is responsible for reading and validating the ATM card, transaction unit for transactions, a currency counter to dispatchcurrency notes to the authorised person and a printer to print the receipt of the transaction done.

Small size and weight: - this is an important factor for choosing a product. For example, when you plan to buy a new mobile phone you make a comparative study on pros and cons of the products available in the market like the size, weight, shape, style etc. Now everyone is demanding for small sized and low weight products.

Power concerns: - This is another important factor that needs to be considered in designing an embedded system. A system should be designed in such a way that it should dissipate very less amount of heat. If the system is heated up in order to cool it we need to use extra equipment like the cooling fans which will make the system bulky. We need to select the system design according to low power components [2][3]. The major challenge is the more the power consumption the less the battery life is.

The embedded system products are used for various purposes depending upon the customer requirements and can be classified as:
- Data storage-collection-representation

- Data communication

- Data processing application

- Monitoring

- Controlling

- Application specific user interface

A typical embedded system comprises of various components

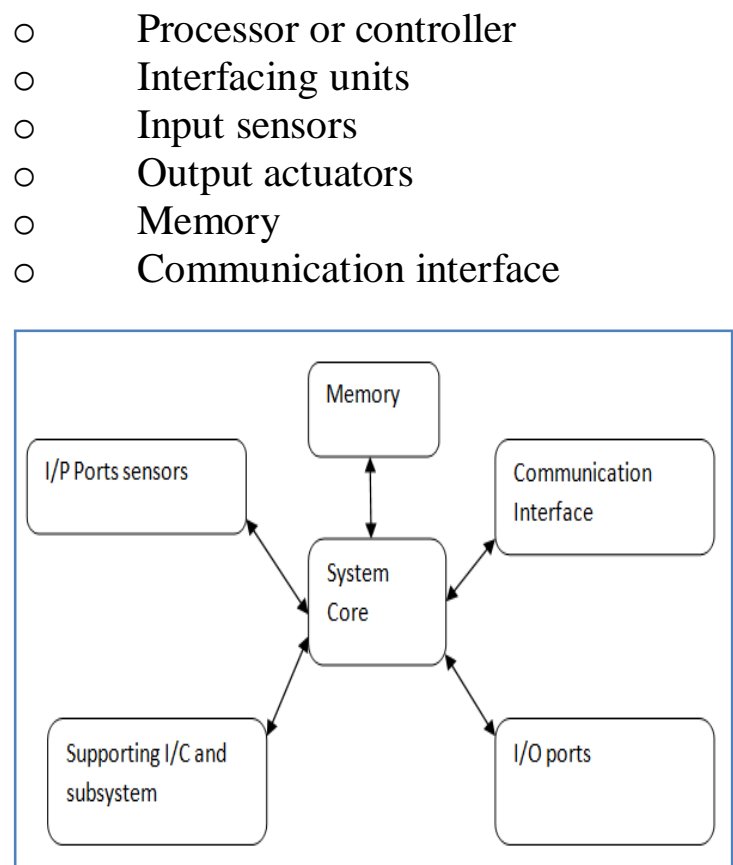

Fig: 2- Components of ES

\section{System Core [processor/controller]}

The system is also known as the central processing or the heart of the embedded system.It is the important component in the elements of embedded system where the programming is done to interface and integrate all the components on the embedded system design [3][1].

\section{Input ports}

These are called as sensors. These are designed to be in contact with the environment and continuously take the input from here and send to the system core. According to the changes in the environment which are fed to the system by the sensors the system core will take a certain action and implement with the help of actuators [2]. 
Website: ijetms.in Issue:4, Volume No.4, July-2020 DOI: 10.46647/ijetms.2020.v04i04.004

\section{Output ports}

They are known as actuators. These are the output devices which will perform the activities like rotation of motor, turn on the switch etc which are instructions given by the system core according to the changes in the environment.

\section{Communication interface}

This communication channel will establish a channel which will interconnect all the components of the system onboard hence also know as onboard communication interface. Examples like I2C, DB-9 etc

\section{Application of Embedded System:}

The application areas and the products in the embedded domain are countless.

\section{Consumer Electronics: Camcorders,} Cameras.

2. Household appliances: Washing machine, Refrigerator.

3. Automotive industry: Anti-lock braking system (ABS), engine control.

4. Home automation \& security systems: Air conditioners, sprinklers, fire alarms.

5. Telecom: Cellular phones, telephone switches.

6. Computer peripherals: Printers, scanners.

7. Computer networking systems: Network routers and switches.

8. Healthcare: EEG, ECG machines.

9. Banking \& Retail: Automatic teller machines, point of sales.

10. Card Readers: Barcode, smart card readers.

\section{REFERENCES:}

[1] http://www.ktunotes.in/ktu-s8-cse-embedde dsystems-notes/

[2] M. Kiran Kumar, S. Jessica Saritha. AN EFFICIENT APPROACH TO QUERY REFORMULATION IN WEB SEARCH, International Journal of Research in Engineering and Technology. 2015;p.172.

[3]Bhargavi, $K$ \& Kumar, $M$ \& Hussan, M.I. \& Stalin, D. (2020). HS2Cloud: A Secure Lightweight Framework for Image Storage on Hybrid Cloud. 